\title{
THE IMPACT OF SOCIOECONOMIC CHARACTERISTICS ON CO 2 EMISSIONS ASSOCIATED WITH URBAN MOBILITY: INEQUALITY ACROSS INDIVIDUALS
}

\author{
Germà Bel i Jordi Rosell \\ (forthcoming Energy Economics)
}

\begin{abstract}
Concerns about the unequal distribution of greenhouse gas emissions attributable to mobility are gaining increasing attention in scholarly analyses as well as in the public policy arena. The factors influencing the emissions of individuals are largely undocumented, but they are assumed to be the same for all, be they low or high emitters. We use a household travel survey conducted in the metropolitan area of Barcelona to differentiate the factors that result in different rates of emission. It shows that the top ten per cent of emitters produce $49 \%$ of total emissions while 'non-daily' emitters make up $38.5 \%$ of the sample. We adopt a quantile regression approach, which reveals significant socioeconomic differences between groups of emitters. Gender, income and homemunicipality type are influential in accounting for $\mathrm{CO}_{2}$ emissions for all groups. Educational level appears to be less significant, and occupation shows no significance at all. The study confirms the ineffective nature of toll policy design in the area. Overall, socioeconomic factors have different impacts on different emitting groups, but these characteristics do not impact equally across all the population. Quantile regression using mobility survey data gathered from various cities would provide useful evidence for improving the design of urban mobility policies.
\end{abstract}

Keywords: Carbon dioxide emissions, climate change mitigation policies, quantile regression

JEL Codes: C31, D12, Q01

\section{Introduction}

Transport is a major contributor to various environmental externalities, including most notably greenhouse gas (GHG) emissions and local air pollution. Indeed, the transport sector is reported to be responsible for a mostly quarter of energy-related carbon dioxide $-\mathrm{CO}_{2}$ - emissions (IEA, 2015). This being the case, it is essential to understand what motivates people to employ (or otherwise) private vehicles, public transportation, and non-motorized modes, respectively. Having obtained this knowledge, appropriate policies can then be designed to enhance transport sustainability. Thus, from a policy perspective, it is important to understand how the distribution of $\mathrm{CO}_{2}$ emissions is related to individual characteristics, since this provides fundamental insights into the distributional implications of climate change mitigation policies. Critically, travel patterns are known to vary in line with socio-economic characteristics, and more specifically with lifestyle characteristics combined with personal preferences and attitudes (Anable, 2005). This makes behavioral change a key factor in reducing the weight of transport in $\mathrm{CO}_{2}$ emissions in relation to other sectors, particularly in the short term (Chapman, 2007).

Increasing attention is being paid to the analysis of international inequality in energy consumption and per capita $\mathrm{CO}_{2}$ emissions (Duro and Padilla, 2006, 2011; Mussini and Grossi, 2015). Furthermore, in recent years a discussion has emerged on how transport 
emissions are distributed very unequal in developed countries (Brand and Boardman, 2008; Brand and Preston, 2010). Thus, some studies have used econometric techniques to differentiate between groups. For example, Ko et al. (2011) identify a group of "high emitters" and, more recently, Büchs and Schnepf (2013) described a group of "low emitters" (although in this case without performing an econometric analysis for this group). Allinson et al. (2016) advocates more work to understand better what causes emissions in households with high total emissions.

This unequal distribution of GHG emissions should have an impact on policy intervention. Changes in aggregate carbon intensity for personal transportation in some OECD countries between the seventies and nineties show the importance of both fuel price and governmental policies in order to contain $\mathrm{CO}_{2}$ emissions (Greening, 2004).

However, most of the research effort to date has focused on the average household, or on high emitter profiles. Thus, attempts at identifying different groups of emitters have been largely neglected and the results describing the distribution of emissions remain inconclusive. For this reason, there continues to be a considerable dearth of knowledge regarding the full implications of policy measures, such as fuel taxes, parking fees, or congestion charges.

This paper seeks to contribute to the literature by examining the impact of a series of individual characteristics on $\mathrm{CO}_{2}$ transport emissions. While most papers to date have analyzed this impact in terms of the average emitter (with a few focusing on the top per cent of high emitters), we analyze the level of $\mathrm{CO}_{2}$ emissions for different population groups. To the best of our knowledge, this is the first econometric analysis using quantiles of transport emitters. To do so, we adopt a quantile regression approach. Our analysis of a sample of 24,605 individuals confirms the unequal distribution of $\mathrm{CO}_{2}$ transport emissions. The top $10 \%$ of high emitters are responsible for $49 \%$ of total emissions, while the top $20 \%$ of pollutants contribute $74 \%$. These are two of the highest rates reported to date in the literature.

We use an institutional household travel survey conducted in the metropolitan area of Barcelona (Catalonia) to identify the factors that allow us to differentiate groups of emitters. This survey includes socioeconomic, demographic, residential, and transport characteristics. After briefly reviewing the related literature in the next section, we report the details concerning our data in section three. We then discuss the econometric methodology of quantile regressions. Thereafter we present the results obtained by using this methodology, comparing it with logistic regressions to check the robustness of our analysis. Then, we conduct the quantile analysis for different mobility policies in a population subsample. Finally, we discuss our main results, examine their policy implications, and draw the main conclusions.

\section{Literature review}

Within the literature on mobility and $\mathrm{CO}_{2}$ emissions, the determination of the type of emitters has gained increasing interest in recent years. Several econometric studies have analyzed transport $\mathrm{CO}_{2}$ emissions and the impact on these of socioeconomic, demographic, geographic and household characteristics. Using econometric methods to analyze how socioeconomic factors influence $\mathrm{CO}_{2}$ transport emissions has gained ground, with the aim to measure the impact of those factors on the amount of $\mathrm{CO}_{2}$ for the average emitter on Quebec City (Barla et al. 2011). Descriptive statistics in Brand and Preston (2010) show that there is an unequal $\mathrm{CO}_{2}$ emissions distribution among individuals, but 
their econometric analysis is performed only on the average emitter for Oxford (UK) citizens. Brand et al. (2013) aim to separate the effect of socioeconomic factors in $\mathrm{CO}_{2}$ emissions, but they just differentiate according to the purpose of the trip, without any differentiation between types of emitter on Oxfordshire (UK). With a similar methodology, and for the UK countrywide, descriptive statistics in Büchs and Schnepf (2013) show differences between high and low emitters, but they conduct OLS regression only on the mean. ${ }^{1}$ Ko et al. (2011) clearly discern on the type of emitter using an econometric approach. By means of logistic regression, significant differences are found between the top $10 \% \mathrm{CO}_{2}$ emitters and the rest of emitters in the Seoul metropolitan area.

Table 1 displays the studies focusing on socio-demographic factors that affect mobility carbon emissions, summarizing their main characteristics and results. On the gender issue, most studies report a positive relation between being male and $\mathrm{CO}_{2}$ emissions: the proportion of high emitters among males being much greater than among females. The impact of income has been widely analyzed in the literature, with the relation always being reported as significant and positive. For example, Büchs and Schnepf (2013) find an elasticity of income- $\mathrm{CO}_{2}$ emissions with respect to income of 0.9. A number of studies (Brand et al., 2013; Büchs and Schnepf, 2013) find a positive relation between $\mathrm{CO}_{2}$ emissions and higher education; yet, higher education can also imply a $\mathrm{CO}_{2}$ reduction, given a greater awareness of environmental issues among the better educated. This might account for the fact that Barla et al. (2011) find higher education not to have a significant relationship with $\mathrm{CO}_{2}$ emissions. In the case of age, most studies find an inverse U-shaped curve; however, age trends are not clear. While adults emit more $\mathrm{CO}_{2}$ than teenagerschildren and retirees, there are marked divergences between these two groups in terms of their emissions. Likewise, it is unclear whether those aged between 18 and 30 emit more or less than the next cohort (up to the age of 45). For example, in Seoul metropolitan area, more than $75 \%$ of high-emitters belong to the 40-to-59-year-old group (Ko et al., 2011).

In relation to factors of mobility, the results are conclusive: holding a car license and, more specifically, owning a car imply more $\mathrm{CO}_{2}$ emissions in all studies. Indeed, the majority of studies show a positive relation between car ownership and income with private car split. Patterns of urban transportation systems and of travel behavior vary widely, even among countries with similar urbanization and per-capita income levels. Santos et al. (2013) find the number of students in universities and higher education to be positively associated with the use of all modes of transport, but the car. Unsurprisingly, they also find that GDP per capita is positively associated with car sharing. Several studies also included the geographic factor as a determinant of emissions related to car dependency. Thus, Büsch and Schenpf (2013) find that downtown or high density areas are associated with lower $\mathrm{CO}_{2}$ emissions. In contrast, lower population densities imply more GHG emissions (Barla et al, 2011), due to an increasing car dependency. However, Brand and Preston (2010) and Brand et al. (2013) find no geographic effects for Oxford and Oxfordshire, respectively. This might be attributed to the fact that people seem to have the need to be involved in particular activities, which do not depend significantly on their immediate spatial environment, defined in terms of relative location vis-à-vis the city center and the nature of the public transportation system (Timmermans, 2003).

\footnotetext{
${ }^{1}$ Another study worth noting is that by Xiao et al. (forthcoming) discern the level of emissions and income on Beijing citizens, but also without separating them on the multilevel regression analysis, being their focus on spatial level. A moderate sample finds that the top 20 percent of emitters are responsible for 65 percent of total emissions. However, because this study uses a survey on energy expenditure, it is not comparable to the studies included in table 1.
} 
Table 1 Impact of different household socio-demographic variables on $\mathrm{CO}_{2}$ transport emissions in previous econometric studies

\begin{tabular}{|c|c|c|c|c|c|c|c|c|c|c|c|c|}
\hline Authors & Year & Zone & Emissions & Method & $\begin{array}{l}\text { Groups } \\
\text { analyze }\end{array}$ & Gender & Income & Education & Age & $\begin{array}{c}\text { Car } \\
\text { ownership }\end{array}$ & $\begin{array}{l}\text { Geographic } \\
\text { zone }\end{array}$ & Others \\
\hline $\begin{array}{c}\text { Brand and } \\
\text { Preston }\end{array}$ & 2010 & $\begin{array}{c}\text { Oxford } \\
\text { (UK) }\end{array}$ & $\begin{array}{l}\text { Transport } \\
\text { emission }\end{array}$ & $\begin{array}{l}\text { Regression } \\
\text { model }\end{array}$ & All & $\ldots$ & $\begin{array}{c}+, \text { but } \\
\text { only } \\
\text { extremes }\end{array}$ & & $\begin{array}{c}\text {... except } \\
\text { negative } \\
\text { on retirees }\end{array}$ & + & $\ldots$. & $\begin{array}{c}\text { - housekeeper, } \\
\text { while no evidence } \\
\text { on retired and } \\
\text { unemployed }\end{array}$ \\
\hline $\begin{array}{l}\text { Barla et } \\
\text { al. }\end{array}$ & 2011 & Quebec city & $\begin{array}{l}\text { Transport } \\
\text { emission }\end{array}$ & $\begin{array}{c}\text { Regression } \\
\text { model }\end{array}$ & All & + & $\begin{array}{c}+, \text { but } \\
\text { only } \\
\text { extremes }\end{array}$ & $\ldots$ & $\begin{array}{c}\text { Less } \\
\text { emissions } \\
50-64 \\
\text { years than } \\
35-49 .\end{array}$ & & $\begin{array}{l}+ \text { for non- } \\
\text { downtown }\end{array}$ & $\begin{array}{c}\text { No car license less } \\
\text { emissions }\end{array}$ \\
\hline Ko et al. & 2011 & $\begin{array}{c}\text { Seoul } \\
\text { metropolita } \\
\mathrm{n} \text { area }\end{array}$ & $\begin{array}{l}\text { Transport } \\
\text { emission }\end{array}$ & $\begin{array}{c}\text { Tree-based } \\
\text { regression and } \\
\text { a binary } \\
\text { logistic model }\end{array}$ & $\begin{array}{l}\text { High emitters } \\
\text { (top 10\%) } \\
\text { and non }\end{array}$ & + & + & & $\cap$ & + & $\begin{array}{l}+ \text { for } \\
\text { metropolitan } \\
\text { cities }\end{array}$ & + working people \\
\hline $\begin{array}{l}\text { Brand et } \\
\text { al. }\end{array}$ & 2013 & $\begin{array}{l}\text { Oxfordshire } \\
\text { (UK) }\end{array}$ & $\begin{array}{l}\text { Transport } \\
\text { emission }\end{array}$ & $\begin{array}{c}\text { Regression } \\
\text { model and } \\
\text { binary logistic } \\
\text { regression }\end{array}$ & $\begin{array}{l}\text { All and high } \\
\text { emitters (top } \\
20 \% \text { ) and } \\
\text { non }\end{array}$ & + & + & + & $\cap$ & + & $\ldots$ & \\
\hline $\begin{array}{c}\text { Büchs and } \\
\text { Schnepf }\end{array}$ & 2013 & UK & All & $\begin{array}{l}\text { Regression } \\
\text { model }\end{array}$ & All & & + & + & $\cap$ & & + rural & \\
\hline
\end{tabular}

Note: +: Positive relation; ...: not significant; $\cap$ : significant for all ages with a maximum on adults; blank: not considered in the analysis

Source: Authors 
Findings for occupational status are clear: those in employment are associated with higher emissions, while being either a homemaker or a retiree implies fewer emissions. However, the impact of being unemployed is less clear - findings suggesting lower emissions or no impact. Another factor taken into account by Büchs and Schnepf (2013) is the composition and number of people in the household, finding that the first child reduces transport emissions, while the second child increases them. All in all, effects assessed in the previous literature commonly work in the same direction, although sometimes the techniques used or the areas researched may cause some variable to lose significance.

Quantile regression has been recently introduced in transport and $\mathrm{CO}_{2}$ empirical analyzes. Qing Su (2012) analyzes the extra utilization of vehicles due to improved fuel efficiency (rebound effect); Hammoudeh et al. (2014) investigate the impact of changes in crude oil prices, natural gas prices, coal prices, and electricity prices on the distribution of the $\mathrm{CO}_{2}$ emission allowance prices in the United States; Bel et al. (2015) measure the impact of speed limits on environmental pollutants. With respect to object of study in this paper, the closest use of the quantile regression methodology is Han et al. (2015) analysis of how household characteristics differ in their associations with household embedded carbon emissions. Without taking into account transport carbon emissions, they find that sociodemographic factors affect GHC emissions differently. It is worth noting that these studies find that independent variables across quantiles have a significant but differential impact on dependent variable. Quantile regression is in a better position to capture the impact of socioeconomic characteristics than OLS. This is particularly relevant when the central location of conditional distribution and tails vary significantly with covariates.

It is worth noting that not all these studies provide the same potential for comparability with Barcelona. ${ }^{2}$ The urban structure and mobility characteristics of the metropolitan area of Barcelona are different from those in Oxford (and Oxfordshire) and Quebec, areas with much lower population and less dense mobility. Also, a study such as Büchs and Schnepf (2013), as it is conducted for a whole country -the UK-, offers little room for comparability. Contrariwise, the Seoul metropolitan area (studied by Ko et al., 2011) is more suitable for comparisons with Barcelona. The density in both central cities is very similar (Seoul 16,500 inhabitants $/ \mathrm{kms}^{2}$; Barcelona, 16,000 inhabitants $/ \mathrm{km}^{2}$ ). Both central cities (and corresponding metro areas) are wealthier and have more income than the rest of the respective countries. Finally, it is also worth noting that the Household Travel Surveys used in Ko et al. (2011) was conducted in 2006, which is precisely the year when the household Survey for the area of Barcelona was conducted.

Overall, the existing evidence points to inconclusive trends and the lack of specific attention to different groups. Therefore, this paper seeks to contribute to the literature by comparing the impact of various individual characteristics on $\mathrm{CO}_{2}$ transport emissions by different emitters. By doing so, we find evidence that not all socioeconomic variables impact equally to all individuals, as well as these variables may have different effects depending on the city analyzed.

\footnotetext{
2 These studies tend to look at the socioeconomic characteristics in a moment of time. An exception to this pattern is that done by Zahabi et al. (2015), conducted for Montreal from 1998 to 2008, paying special attention to geographic characteristics -rather than socioeconomic ones-. They find emissions reduction over time, due to distance travelled reduction, and efficiency improvement of the fleet.
} 


\section{Data}

\subsection{Barcelona metropolitan area and mobility-related characteristics}

The Barcelona metropolitan area is home to 3 million people and occupies a surface area of $636 \mathrm{~km}^{2}$. This makes it one of the largest metropolitan areas in Europe, while it ranks eighth in terms of population. The metropolitan area presents two forms of urbanization and land use. In the metropolitan core, Barcelona and its neighboring municipalities constitute a continuous, compact urban area with mixed urban functions, whereas its periphery is characterized by low population density, a less compact urban area and a less specialized urban function by zone. Population density decreases as we move out from Barcelona and away from the highways (Garcia-López, 2010), whereas housing affordability increases with distance to the Barcelona city center. Only $20 \%$ of inhabitants rent their dwellings; the others are owner-occupiers. There is low residential mobility for purposes of work.

The metropolitan area is structured around a radial transport network, with the principal agglomerations of population and employment connected to the center of Barcelona by means of railway lines and metropolitan highways. Public transport fares are not linked to distance and most of the population lives in the same fare zone, with a very small percentage living in the second fare zone. A single ticket allows passengers to switch from one mode of transport to another to reach their required destination. There are eight motorway access roads to the inner city. Two of these are tolled, and in one case there is a toll-free alternative route. The other six motorways are toll-free. Tolls are fixed by taking various financial factors into account, including the concessionaires' investment, maintenance expenses and the recovery of other costs. Environmental considerations play no role in the tolls charged. Overall, the main factors accounting for the mobility carbon footprint in Barcelona are population density and accessibility, while the average municipal family income and job ratio are not as important (Muñiz and Galindo, 2005).

Each municipality regulates its own parking policies. However, land use parking policies are the responsibility of the broader territorial entity, the Àrea Metropolitana de Barcelona (AMB). In the case of all new housing developments, one parking space must be provided for every apartment unit. Curbside parking regulations are implemented in most cases in the city centers of each municipality. Barcelona has operated curbside parking since the 1980s. This has expanded over the years, and today is combined with residential permits (see Gragera and Albalate, 2016). In the metropolitan area as a whole, off-street parking amounts to two-thirds of total supply - split between private (2/3) and public access (1/3). The remaining third is made up of curbside and 'free' on-street parking.

\subsection{Data source}

Our main data base is the household travel survey (HTS) conducted for the entire metropolitan region of Barcelona in 2006 by the Metropolitan Transport Authority (Institut d'Estudis Regionals $i$ Metropolitans de Barcelona, 2006). This data base includes a sample of individuals reporting their previous day's (daily) trips, including origin and destination, journey time, day and hour, transport mode, and trip purpose. The survey employs a computer-assisted telephone interviewing (CATI) technique in contacting with a representative sample of the population. Using a multistage stratified 
sampling, individuals are selected by applying sex and age quotas. The interview comprises four blocks of questions: the first block concerns household composition and is used to select the individual; the second block of questions gathers details about all the previous day's trips; the third block comprises questions about the individual's socioeconomic characteristics; and, the fourth block gather personal details related to the individual's mobility. The individual characteristics gathered in the third block are gender, age, educational level, family income, and occupational status. The fourth block gathers financial information, including monthly expenditure on public transport, fuel, tolls, and parking away from home. We compute all journeys within the metropolitan area of Barcelona, that is, all metropolitan journeys that have their origin and destination inside the area. The total number of journeys is 93,864 , and the total number of travelers is 24,605. All types of journey (be they for leisure, work, shopping, etc.) are included.

\subsection{Emissions estimation procedure}

$\mathrm{CO}_{2}$ intensity is a measure of emissions per unit of activity, and is calculated using the estimation procedure employed by the International Transport Forum (2009). For private cars, we also use the emission factors, corrected by the proportion of gasoline and diesel vehicles making up the fleet. The regional government provides different emission factors according to three average speeds: $21 \mathrm{~km} / \mathrm{h}, 70 \mathrm{~km} / \mathrm{h}$, and $107 \mathrm{~km} / \mathrm{h}$. We obtain different emission factors based on road type (urban, interurban, or motorway), time slot, and city of origin and destination. The emission factor is corrected if the individual is accompanied by a traveling companion, depending on the metropolitan occupancy rate. $\mathrm{CO}_{2}$ emissions are calculated using equation 1 :

$$
\mathrm{CO}_{2} \text { private mode }=\text { Emission time } x \text { emission factor (speed) } x \text { Occupancy }
$$

We conduct the same procedure for motorbikes, except that there are no diesel vehicles among this mode of transport. Emissions from soft modes, cycling and walking, are categorized as zero. In the case of taxis, we have information on the emission factor of each vehicle type and the composition of the fleet, and we also correct for traffic conditions. For subways, tramways, interurban buses, and national and regional trains, we use the official emission factors (for passenger-kilometers) applying equation 2:

$$
\mathrm{CO}_{2} \text { public transport }=\text { Distance } x \text { emission factor }
$$

For intra-city bus journeys, we only have information about journey time, so we apply equation 1 . Therefore, to obtain the corresponding $\mathrm{CO}_{2}$ emissions we discount walking (transit access) time and apply an average speed.

The first limitation we encounter (and one that we need to take into account when interpreting our results) concerns those individual commuters that switch transport modes when completing the same trip. The HTS does not indicate where these changes of transport mode occur; thus, it is not possible to quantify their $\mathrm{CO}_{2}$ emissions accurately. There is no way of overcoming this limitation, so we opted to omit these individuals. ${ }^{3}$ Additionally, information on several variables is unavailable - this is the case of car and motorbike ownership, and household size (in particular, the number of children and their ages).

\footnotetext{
${ }^{3}$ It is worth noting that there are not differences between individuals in both samples, with respect to socioeconomic characteristics.
} 


\subsection{Emission results}

Based on the available information and making the computations outlined above, we find that the individual, daily average emission is $1,738 \mathrm{~g} \mathrm{CO}_{2}$. The top $10 \%$ of pollutants are responsible for $49 \%$ of total emissions, that is, $8,961 \mathrm{~g} \mathrm{CO}_{2}$ per day, while the top $20 \%$ of pollutants contribute $74 \%$ of total emissions (Figure 1). These results are consistent with the literature: top ten per cent of emitters produce 43 and $63 \%$ of emissions in Oxford and Seoul, respectively. If we focus on the highest quintiles only, we find they produced 62 and $82 \%$ of total emissions in Oxford and Seoul, respectively (Brand and Preston, 2010; Ko et al., 2011).

In Barcelona, $38.5 \%$ of individuals do not produce $\mathrm{CO}_{2}{ }^{4}$ These findings point to considerable inequality in daily mobility emissions, presenting a coefficient of 0.496 on the Gini index. If we compare this with the income-related Gini index for 2006 for the same area (recorded at 0.296), the inequality for mobility emissions is twenty points higher and, as such, is much more pronounced. The Jarque-Bera test indicates that individual emissions do not follow a normal distribution ( $\mathrm{p}$-value equal to zero). On average, $86 \%$ of the emissions attributable to an individual emitter are produced by private vehicles. Average emissions per journey in a private vehicle are $1,258 \mathrm{~g} \mathrm{CO}_{2}$, while emissions per journey on public transportation are $439 \mathrm{~g} \mathrm{CO}_{2}$.

Figure 1 Cumulative distribution of total daily $\mathrm{CO}_{2}$ mobility emissions

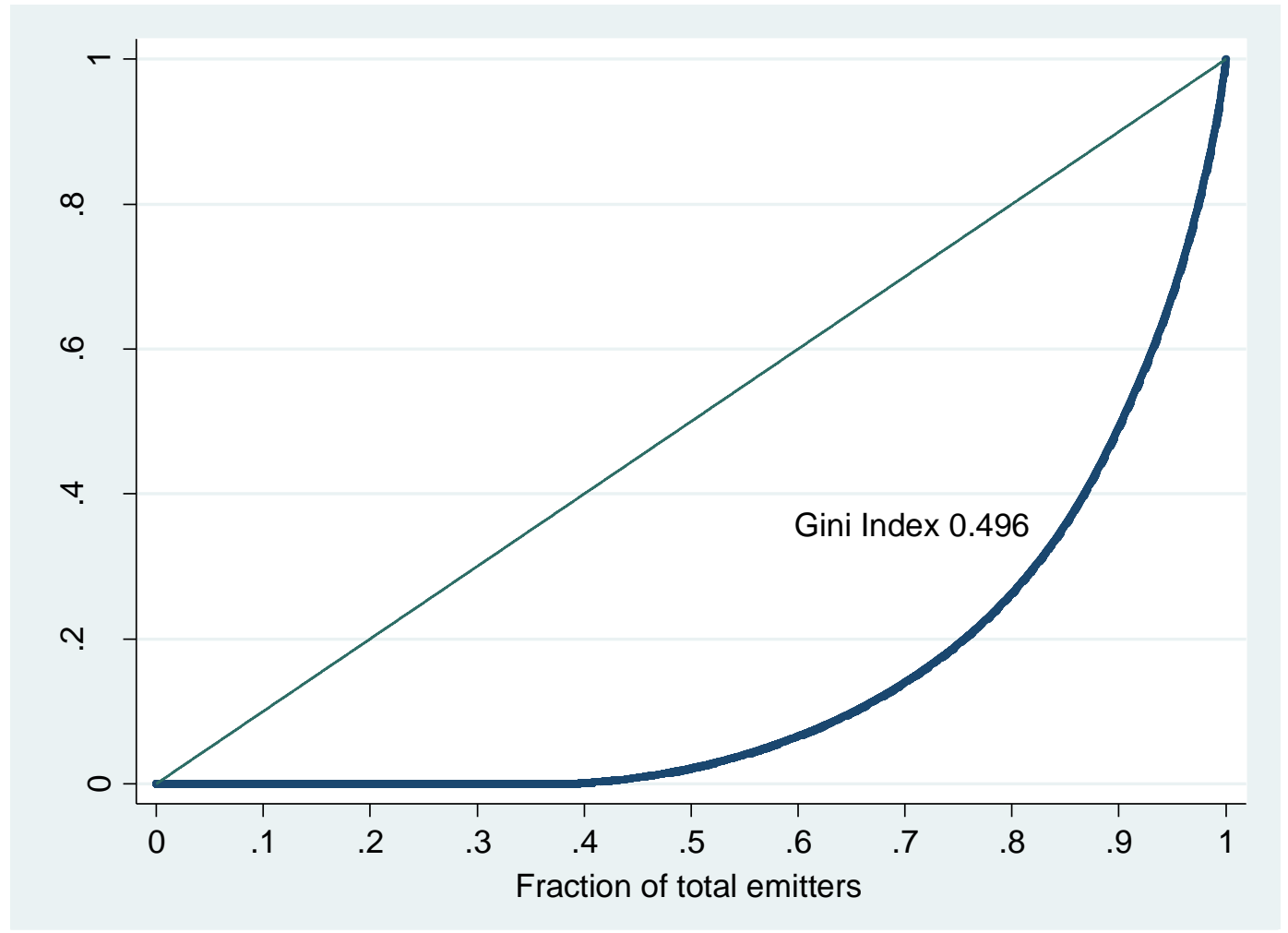

Source: Authors

Table 2 shows the socioeconomic traits considered: sex, monthly family income, educational level, occupation status, size of hometown, and monthly expenditure on

\footnotetext{
${ }^{4}$ The low proportion of non-emitters is due to the sampling method. The travel survey only asks about the trips undertaken the previous day.
} 
different transportation alternatives: public transportation, car fuel, tolls, and parking away from home (i.e., all parking expenditure, except home parking). The 10th and 25th percentiles cluster the non $\mathrm{CO}_{2}$ emitters; the 50th percentile corresponds to the median emitter and 0.69 to the average emitter - hence, the 75 th quantile can be interpreted as such.

Table 2 Mean and standard deviations of socioeconomic characteristics

\begin{tabular}{|c|c|c|c|c|c|c|}
\hline \multirow{2}{*}{$\begin{array}{l}\text { Family } \\
\text { variables }\end{array}$} & \multirow[t]{2}{*}{ Variable } & \multirow{2}{*}{ Levels } & \multicolumn{4}{|c|}{ Quantile } \\
\hline & & & 0.25 & 0.5 & 0.75 & 0.9 \\
\hline \multirow{10}{*}{$\begin{array}{c}\text { Demo } \\
\text { geographic }\end{array}$} & \multirow[t]{2}{*}{ Gender } & Male & $0.421(0.4936)$ & $0.407(0.4915)$ & $0.476(0.4996)$ & $0.627(0.4839)$ \\
\hline & & Female & $0.579(0.4936)$ & $0.593(0.4915)$ & $0.524(0.4996)$ & $0.373(0.4839)$ \\
\hline & \multirow{4}{*}{ Age } & $4-29$ & $0.311(0.4629)$ & $0.458(0.4984)$ & $0.312(0.4635)$ & $0.199(0.3991)$ \\
\hline & & $30-44$ & $0.166(0.3724)$ & $0.203(0.4021)$ & $0.318(0.4660)$ & $0.446(0.4973)$ \\
\hline & & $45-64$ & $0.252(0.4340)$ & $0.215(0.4107)$ & $0.267(0.4426)$ & $0.301(0.4589)$ \\
\hline & & Above 65 & $0.271(0.4445)$ & $0.124(0.3301)$ & $0.102(0.3033)$ & $0.054(0.2261)$ \\
\hline & \multirow{4}{*}{$\begin{array}{l}\text { Hometown } \\
\text { Inhabitants }\end{array}$} & Barcelona & $0.392(0.4882)$ & $0.486(0.5000)$ & $0.384(0.4865)$ & $0.320(0.4667)$ \\
\hline & & $<10,000$ & $0.027(0.1620)$ & $0.056(0.2304)$ & $0.069(0.2541)$ & $0.048(0.2131)$ \\
\hline & & $10,000-50,000$ & $0.152(0.3588)$ & $0.138(0.3448)$ & $0.161(0.3675)$ & $0.178(0.3826)$ \\
\hline & & $>50,000$ & $0.429(0.4950)$ & $0.319(0.4666)$ & $0.386(0.4871)$ & $0.454(0.4981)$ \\
\hline \multirow{15}{*}{ Economic } & \multirow{6}{*}{$\begin{array}{l}\text { Family monthly } \\
\text { income }\end{array}$} & Less than $1000 €$ & $0.371(0.4830)$ & $0.216(0.4117)$ & $0.136(0.3429)$ & $0.073(0.2611)$ \\
\hline & & $1000-2000 €$ & $0.404(0.4907)$ & $0.400(0.4903)$ & $0.419(0.4936)$ & $0.394(0.4889)$ \\
\hline & & $2000-3000 €$ & $0.151(0.3578)$ & $0.240(0.4276)$ & $0.271(0.4446)$ & $0.311(0.4631)$ \\
\hline & & $3000-4000 €$ & $0.050(0.2179)$ & $0.077(0.2660)$ & $0.114(0.318)$ & $0.135(0.3420)$ \\
\hline & & $4000-5000 €$ & $0.015(0.1209)$ & $0.042(0.2015)$ & $0.041(0.1974)$ & $0.046(0.2089)$ \\
\hline & & $>5000 €$ & $0.010(0.1006)$ & $0.025(0.1549)$ & $0.019(0.1392)$ & $0.041(0.1977)$ \\
\hline & \multirow{4}{*}{ Educational level } & No studies & $0.145(0.3523)$ & $0.068(0.2530)$ & $0.033(0.1784)$ & $0.012(0.1087)$ \\
\hline & & Primary studies & $0.480(0.4996)$ & $0.373(0.4838)$ & $0.319(0.4662)$ & $0.264(0.4407)$ \\
\hline & & Second studies & $0.238(0.4253)$ & $0.340(0.4738)$ & $0.3854(0.4869)$ & $0.397(0.4895)$ \\
\hline & & Tertiary studies & $0.137(0.3441)$ & $0.219(0.4139)$ & $0.263(0.4404)$ & $0.327(0.4693)$ \\
\hline & \multirow{5}{*}{ Occupation status } & Scholar & $0.251(0.4332)$ & $0.348(0.4766)$ & $0.168(0.3739)$ & $0.055(0.2277)$ \\
\hline & & Housekeeper & $0.122(0.3276)$ & $0.064(0.2465)$ & $0.055(0.2284)$ & $0.029(0.1689)$ \\
\hline & & Retiree & $0.304(0.4601)$ & $0.145(0.3521)$ & $0.121(0.3267)$ & $0.069(0.2537)$ \\
\hline & & Employed & $0.268(0.4428)$ & $0.408(0.4916)$ & $0.602(0.4897)$ & $0.803(0.3979)$ \\
\hline & & Unemployed & $0.055(0.2286)$ & $0.034(0.1814)$ & $0.054(0.2252)$ & $0.044(0.2044)$ \\
\hline \multirow{4}{*}{\multicolumn{2}{|c|}{$\begin{array}{c}\text { Mobility } \\
\text { expenditure }\end{array}$}} & Public transport & $13.22(16.026)$ & $24.42(20.959)$ & $22.75(24.328)$ & $14.76(25.838)$ \\
\hline & & Fuel & $47.86(44.076)$ & $47.82(54.001)$ & $59.60(80.087)$ & $84.00(74.316)$ \\
\hline & & Tolls & $10.37(20.134)$ & $13.21(24.014)$ & $11.16(22.907)$ & $14.36(31.950)$ \\
\hline & & Parking away home & $5.22(16.195)$ & $7.44(17.92)$ & $8.38(22.135)$ & $15.49(33.665)$ \\
\hline \multicolumn{3}{|c|}{ Number of daily journeys } & $3.74(1.819)$ & $3.57(1.650)$ & $3.862(1.772)$ & $4.05(2.055)$ \\
\hline
\end{tabular}

Source: Authors

The average daily $\mathrm{CO}_{2}$ mobility emissions per capita are unequally distributed geographically (Figure 2). The lowest emission are recorded in the city of Barcelona and the contiguous area, whereas the highest emissions are recorded in the municipalities located furthest from the inner city, characterized by relatively low population densities and poor public transport networks. This is consistent with the findings of Muñiz and Galindo (2005), who studied the ecological footprint in the metropolitan area of Barcelona and found that municipalities with low-density levels located in the outer periphery have higher per capita daily mobility emissions than municipalities located in denser, more central areas. 
Figure 2 Geographical distribution of average daily $\mathrm{CO}_{2}$ mobility emissions

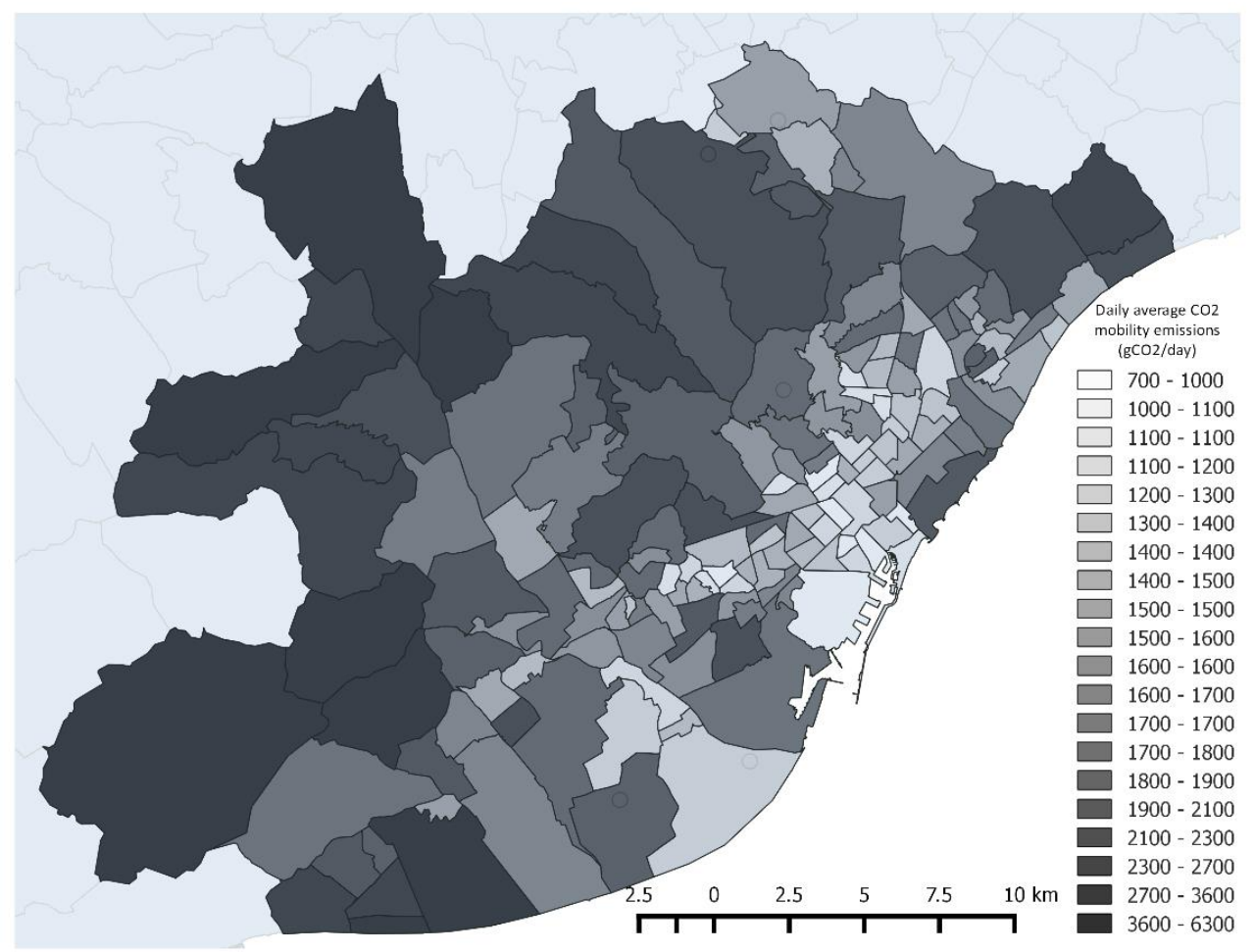

Source: Authors

\section{Methods}

We use quantile regression to investigate the characteristics of individuals depending on their $\mathrm{CO}_{2}$ emission levels. Quantile regression was first introduced by Koenker and Bassett (1978) as an extension of the notion of ordinary quantiles (or "percentiles") in a location model. In this way, the regression model can be extended to conditional quantiles of the response variable. Quantile regression is especially useful when the rate of change in the conditional quantile, expressed by the regression coefficients, depends on the quantile. Thus, we can study the whole distribution of the collected data rather than simply the mean. This makes it particularly valuable for applications in which extremes are important or which differ markedly from the mean. Quantile-based estimators are more robust and more efficient than mean estimators when distributions have fat tails: quantiles estimations are preferred than OLS ones Equations are designed to estimate the relation of covariates. Two important features of the estimation are that quantile regression is more robust to non-normal errors as well as to outliers. ${ }^{5}$

The linear model is defined as:

$$
Q_{Y_{i}}(\tau)=\beta(\tau) X_{i}+\theta_{i}
$$

where $Q_{Y_{i}}(\tau)$ is the quantile function at confidence level. The model in (3) allows the influence of covariates $X_{i t}$ to depend on the quantile level $\tau .{ }^{6}$ As proposed in Koenker

\footnotetext{
5 As discussed by Deaton (1997), quantile regression is most useful when the errors are heteroscedastic.
}

${ }^{6}$ See Bel et al. (2015) for a detailed explanation of the quantile regression method. 
(2004), we want to estimate the parameters in model (1) simultaneously for all quantiles under study, $\tau_{q}, q=1, \ldots, Q$. Following Koenker (2004) this implies solving:

$$
\min _{(\beta, \gamma, \theta)} \sum_{q=1}^{Q} \sum_{i=1}^{n} \sum_{t=1}^{T_{i}} w_{q} \rho_{\tau_{q}}\left(Y_{i t}-\beta\left(\tau_{q}\right) X_{i t}--\theta_{i}\right)
$$

where $\rho_{\tau}(\cdot)$ is a function defined by Koenker and Bassett (1978) as:

$$
\rho_{\tau}(u)= \begin{cases}\tau|u|, & u \geq 0 \\ (1-\tau)|u|, & u<0\end{cases}
$$

The terms $w_{q}$ are weights. They control the influence of the quantiles on the estimation of the fixed effects. We assume that the weights are the same for all the quantiles we analyze. We opted here to regress the $25^{\text {th }}, 50^{\text {th }}, 75^{\text {th }}$ and $90^{\text {th }}$ quantiles. Equations are designed to estimate the relation between socioeconomic characteristics and mobility expenditure and the $\mathrm{CO}_{2}$ individual emission, conditional on quantiles of $\mathrm{CO}_{2}$ individual emission.

\section{Results}

\subsection{Quantile regression}

In this model, all the explanatory variables are categorical variables; thus, one class of each variable was designated as a reference. As we are aware that multicollinearity problems might affect some of these variables, we conducted the VIF test on the simple model, and found three - secondary education, retirees, and employed - with values between five and eight. Indeed, the results for the variables related to occupational status presented considerable instability in all estimations. In distribution tests of the dependent variable, normality is always rejected; therefore quantile regression is preferred to OLS models. We performed the Machado-Santos Silva (2000) test to detect heteroscedasticity. The assumption that residuals are normally distributed is violated owing to the multiple cases of non-emitters in our sample, as such the presence of heteroscedasticity is confirmed. We performed quantile regression and found robust standard errors and $\mathrm{t}$ statistics that are asymptotically valid under heteroscedasticity using the Machado et al. (2011) package. Additionally, we include the results from the OLS regression so that we can compare the sign and the significance of the variables obtained with each methodology. ${ }^{7}$

First, when using quantile regression, the explanatory power of the estimations for the groups of higher emitters increases. In fact, our results are poor for the groups of lower emitters. We omit the $25^{\text {th }}$ quantile from Table $3 \mathrm{a}$ as the pseudo- $\mathrm{R}^{2}$ was below 0.02 and because of the poor performance of most explanatory variables (results available upon request). In contrast, we obtain a relatively high explanatory power of the estimations for the highest quantiles ranges between 0.14 and $0.16 .^{8}$ All in all, socioeconomic variables have a limited ability to capture the variability of individual $\mathrm{CO}_{2}$ emissions. Indeed, the

\footnotetext{
${ }^{7}$ As the presence of heteroscedasticity is confirmed, we use robust (White) standard errors when conducting the OLS regressions.

${ }^{8}$ As mentioned above, besides the influence of socioeconomic characteristics on travel patterns, the latter are known to vary greatly according to lifestyle characteristics combined with personal preferences and attitudes (Anable, 2005; Chapman, 2007).
} 
model based on these socioeconomic variables fails to discern with sufficient precision between those who are high emitters and those who are not.

Demo-geographic variables: Males produce more $\mathrm{CO}_{2}$ mobility emissions than females in all quantiles. This is an extremely robust result: the emissions for being male increase over the quartiles. Age is a significant and positive factor for people aged between 30 and 44 , while in the other population groups there are no significant differences. Emitters resident in small municipalities emit significantly more (followed by individuals in medium and large municipalities) than do those resident in Barcelona, as Figure 2 also shows. Individuals living in highly populated areas produce less daily mobility emissions, but their emissions from long-distance trips are greater than those produced by individuals living in rural areas, as Reichert et al. (2016) report. In terms of median values, there are no statistical differences between municipalities above 10,000 inhabitants and Barcelona (although OLS indicates a significant effect).

Table 3 Quantile regression

\begin{tabular}{|c|c|c|c|c|c|c|}
\hline $\begin{array}{l}\text { Family } \\
\text { variables }\end{array}$ & $\begin{array}{l}\text { Variable } \\
\text { (reference level) }\end{array}$ & Levels & OLS & 0.5 & 0.75 & 0.9 \\
\hline \multirow{7}{*}{$\begin{array}{l}\text { Demo } \\
\text { geographic }\end{array}$} & Gender (Female) & Male & $909.3 * * *(49.08)$ & $227.9 * * *(42.0)$ & $1,067.3^{* * * *}(87.6)$ & $1,661 * * *(149.9)$ \\
\hline & Age (Under 30) & $30-44$ & $328.8 * * *(85.08)$ & $93.06 *(56.3)$ & $604.8 * * *(154.0)$ & $876.4 * * *(235.1)$ \\
\hline & & $45-64$ & $53.07(88.91)$ & $-59.61(54.1)$ & $44.7(156.8)$ & $313.3(223.4)$ \\
\hline & & Above 65 & $16.34(108.60)$ & $-59.61(56.1)$ & $44.7(162.8)$ & $108.9(245.2)$ \\
\hline & Hometown & $<10,000$ & $1,289 * * *(133.11)$ & $696.0 * * *(122.6)$ & $1,510 * * *(233.1)$ & $2,708 * * *(465.1)$ \\
\hline & Inhabitants & $10,000-50,000$ & $597.4 * * *(73.71)$ & $1.39 \mathrm{e}-11(25.1)$ & $313.8 * * *(100.2)$ & $989.8 * * *(184.5)$ \\
\hline & (Barcelona) & $>50,000$ & $588.5 * * *(51.20)$ & $1.73 \mathrm{e}-11(18.0)$ & $403.1 * * *(68.1)$ & $770.7 * * *(110.2)$ \\
\hline \multirow[t]{12}{*}{ Economic } & Family monthly & $1000-2000 €$ & $267.1 * * *(53.66)$ & $1.33-11(17.5)$ & $255.5 * * *(73.7)$ & $496.2 * * *(136.4)$ \\
\hline & income $(<1000 €)$ & $2000-3000 €$ & $655.0 * * *(76.29)$ & $317.8 * * *(48.4)$ & $894.0 * * *(135.4)$ & $1,470 * * *(240.3)$ \\
\hline & & $3000-4000 €$ & $787.7 * * *(106.35)$ & $519.2 * * *(95.0)$ & $1,397.1 * * *(172.7)$ & $1,591 * * *(266.0)$ \\
\hline & & $4000-5000 €$ & $1,303 * * *(191.69)$ & $647.5^{* * *}(156.4)$ & $1,727.2 * * *(224.7)$ & $3,262 * * *(514.0)$ \\
\hline & & $>5000 €$ & $1,517 * * *(200.78)$ & $1,277.13 * * *(428.2)$ & $2,509.4 * * *(406.2)$ & $2,997 * * *(435.6)$ \\
\hline & Educational level & Primary studies & $236.6 * * *(50.51)$ & $1.18 \mathrm{e}-10(14.6)$ & $3.05 \mathrm{e}-10(38.6)$ & $634.5 * * *(81.8)$ \\
\hline & (no studies) & Second studies & $580.2 * * *(71.68)$ & $133.6^{* * *}(29.1)$ & $460.1 * * *(88.2)$ & $1,510 * * *(191.7)$ \\
\hline & & Tertiary studies & $457.0 * * *(85.25)$ & $1.70 \mathrm{e}-10(40.3)$ & $218.6^{* *}(100.9)$ & $1,170 * * *(210.3)$ \\
\hline & Occupation status & Housekeeper & $-216.5^{*}(129.21)$ & $-292.9 * * *(74.7)$ & $-258.6(199.2)$ & $-730.6^{* *}(347.4)$ \\
\hline & (student) & Retiree & $-393.5 * * *(137.38)$ & $-292.9 * * *(76.6)$ & $-258.6(200.2)$ & $-646.6^{*}(358.0)$ \\
\hline & & Employed & $955.6^{* * *}(114.07)$ & $723.0 * * *(70.0)$ & $1,736 * * *(165.0)$ & $2,219 * * *(313.1)$ \\
\hline & & Unemployed & $-51.35(140.12)$ & $-204.5 * * *(77.4)$ & $-35.41(201.5)$ & $-58.6(372.9)$ \\
\hline \multirow{3}{*}{\multicolumn{3}{|c|}{$\begin{array}{l}\text { Observations } \\
\text { Pseudo } \mathbf{R}^{2} \\
\text { Machado-Santos Silva test }\end{array}$}} & 16,409 & 16,409 & 16,409 & 16,409 \\
\hline & & & 0.146 & 0.1259 & 0.1405 & 0.1574 \\
\hline & & & & 1630.23 & 1100.73 & 577.73 \\
\hline
\end{tabular}

Significance levels: * 10 per cent; $* * 5$ per cent; $* * * 1$ per cent (standard errors are presented in parentheses) Source: Authors

Economic variables: Income is highly significant in all quantiles and for almost all categories. The level of education seems to follow an inverted U-shaped curve in some quantiles, which is consistent with findings in Santos et al. (2013) for European cities, where the more highly educated tend to be associated with a higher proportion of low emitting modes and with greater public transport use. A divergence is found between OLS and quantile outcomes in relation to the impact of primary education: OLS identifies a positive effect of primary education vs no-education, while at the 0.5 and 0.75 quantiles there is a non-effect.

In Figure 3 we plot the estimated coefficients for different quantiles and variables, and their $95 \%$ confident interval. ${ }^{9}$ We only plot variables whose quantile and OLS estimates differ. Superimposed on the plot we represent the ordinary least squares estimation of the

\footnotetext{
${ }^{9}$ Stata software does not allow us to perform robust standard errors. Figure 2 includes standard errors obtained using the simultaneous interquantile procedure, with the same weight for each quantile.
} 
mean effect (dashed line), and the $90 \%$ per cent confidence interval (dotted lines). The graph illustrates how the impact on daily $\mathrm{CO}_{2}$ emissions of the demo-geographic and economic variables vary over quantiles, and how the magnitude of these effects at various quantiles differ considerably from the corresponding OLS coefficient, even in terms of the confidence intervals around each coefficient. Note also that these coefficients are significantly different from zero for most quantiles, especially for the highest ones, while these coefficients are zero for the low quantiles. By way of example, this means being male, living in a medium-sized municipality and having tertiary education impacts differently. Thus, a policy design that focuses solely on higher educated individuals or males would be erroneous because these are not differentiating factors. Note that the quantile regression estimates lie at some point outside the confidence interval for OLS, suggesting that covariate impacts are not the same for all emitters. These results support our hypothesis that the majority of socioeconomic factors do not have an equal impact on individuals' emissions and emitter types need to be separated. This finding is typically ignored when using models that only consider average pollutant households or high emitters. In contrast, by using quantile regression we are able to analyze these differential impacts.

Furthermore, for most of the variables and the top quantiles we obtain higher confidence bands. As such, high emitters appear to be less predictable than other groups of emitters. In general, and as we have discussed above, differential impacts are found when we compare the extreme quantiles and the average emitter. Here again, the use of quantile regression enables us to take these differences into account and to analyze their dimensions.

Figure 3: Selection of estimated socioeconomic parameters by quantile with $95 \%$ confidence limits
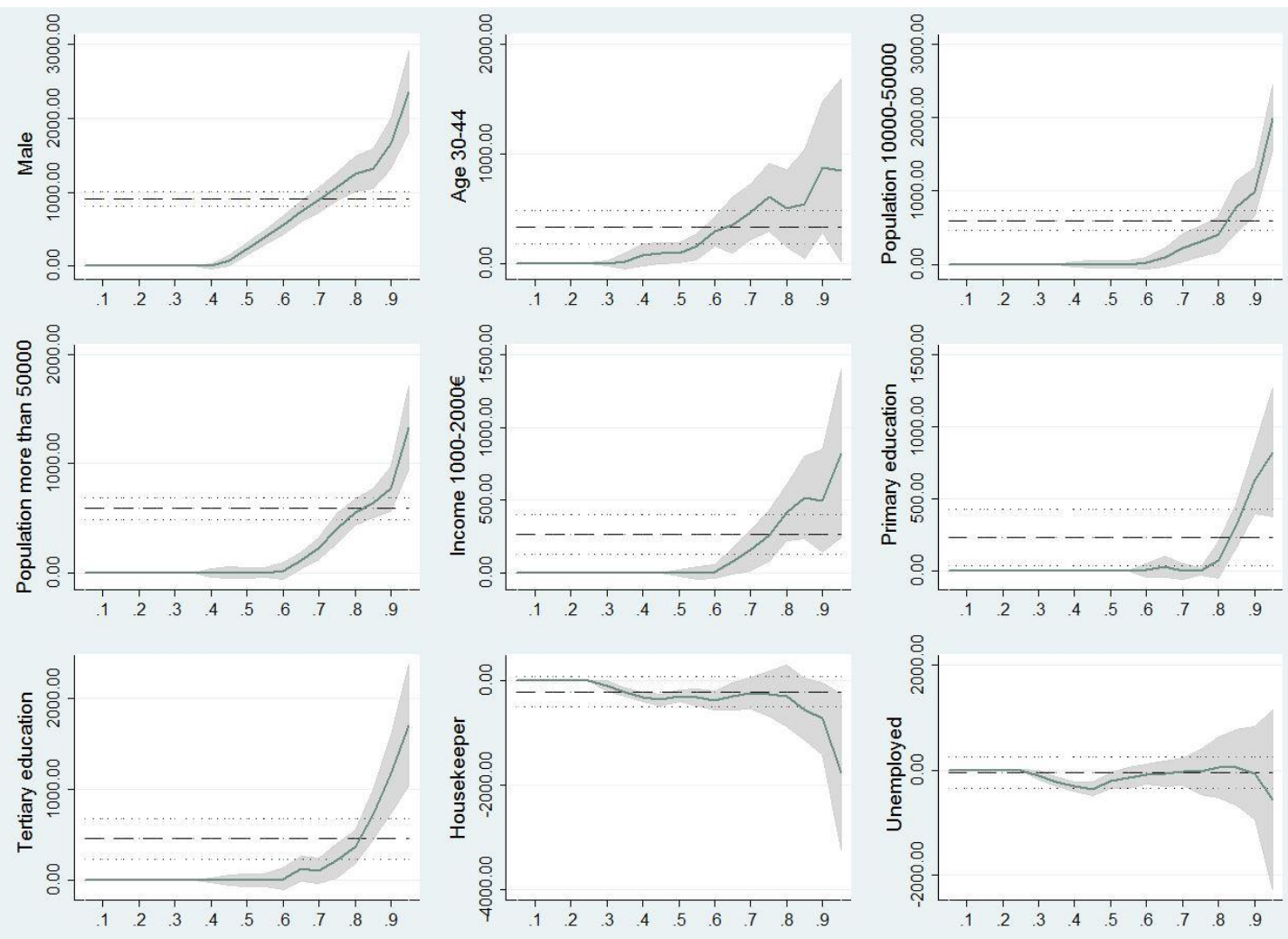

Source: Authors 


\subsection{Logistic regressions}

We regress logit models in investigating the characteristics of individuals in order to check the robustness of our previous results. We sort the individuals according to their daily $\mathrm{CO}_{2}$ transport emissions and then classify them as either high emitters (top 10\%) and non-high emitters (other 90\%). Following the method used by Ko et al. (2011) for high emitters in the Seoul metropolis area, we create a dichotomous variable with a value of 1 if the individual is a high emitter and 0 otherwise. The top $10 \%$ of emitters are responsible for $49 \%$ of total $\mathrm{CO}_{2}$ mobility emissions, producing more than 5,532 $\mathrm{g} \mathrm{CO}_{2}$ per day. Additionally, we undertake a second classification creating a second dummy variable: non-emitters (bottom 38.5\%) given a value of one, and zero otherwise (remaining 61.5\%).While the logistic regression conducted on the high emitters serves as a robustness check, the non-emitter logistic regression adds new information as the lower quantiles were not previously considered.

A binary logistics model allows us to examine the way in which socioeconomic characteristics affect an individual's probability of being a high emitter and, in the other model, their probability of being a non-emitter. Table 4 shows the impacts of the demogeographic and economic variables on individual mobility emissions. Note the pseudo$\mathrm{R}^{2}$ value of $0.118-0.122$ cannot be considered low, as we conduct logistic regressions. In addition, the Hosmer-Lemeshow statistic for 10 groups suggests that the model fits the model specification satisfactorily.

High emitters: The odds of a male being a high emitter are $112 \%$ higher than those of a female. Age only presents a clear pattern in the case of the 30- to 44-year olds, who present a higher probability of being high emitters. For those older than 65 , the probability of being a high emitter decreases in comparison with those under the age of 30. Living outside the city of Barcelona increases the probability of being a high emitter. Furthermore, individuals in Barcelona present a lower probability of being high emitters. Family monthly income presents a clear pattern, with the probability of being a high emitter increasing with income. For a top income family, the odds of being a high emitter are four times higher than those for a family with less than $1000 €$ per month. The probability of being a high emitter also increases with level of education. However, overall this factor appears to present an inverted U-shaped curve, since those with secondary education are more likely to be high emitters of $\mathrm{CO}_{2}$ than those with tertiary education. In relation to occupational status, being employed significantly increases the probability of being a high emitter compared to the reference group of students, but no other significant differences are found (except being a homemaker decreases the probability).

Non-emitters: The results for non-emitters are clearer than those for high-emitters, with the outcomes for most variables being the inverse of those obtained for high emitters. Thus, being male decreases the probability of being a non-emitter, while those in the upper age levels are more likely to be non-emitters. A higher income and a higher level of education are associated with a lower probability of being in this group. Homemakers and retirees have odds of $150 \%$ of being non-emitters compared to the reference group of students. However, having a job reduces the probability of being a non-emitter by $25 \%$. 
Table 4 Logistic regressions on high emitters

\begin{tabular}{|c|c|c|c|c|c|c|}
\hline \multirow[t]{2}{*}{$\begin{array}{l}\text { Family } \\
\text { Variable }\end{array}$} & \multirow[t]{2}{*}{$\begin{array}{c}\text { Variable (reference } \\
\text { level) }\end{array}$} & \multirow[t]{2}{*}{ Levels } & \multicolumn{2}{|c|}{ High emitters } & \multicolumn{2}{|c|}{ Non emitters } \\
\hline & & & $\begin{array}{l}\text { Coefficient } \\
\text { (Standard error) }\end{array}$ & $\begin{array}{l}\text { Odds- } \\
\text { ratio }\end{array}$ & $\begin{array}{l}\text { Coefficient } \\
\text { (Standard error) }\end{array}$ & $\begin{array}{l}\text { Odds- } \\
\text { ratio }\end{array}$ \\
\hline \multirow{7}{*}{$\begin{array}{l}\text { Demo } \\
\text { geographic }\end{array}$} & Gender (Female) & Male & $0.750 * * *(0.054)$ & 2.117 & $-0.202 * * *(0.039)$ & 0.817 \\
\hline & Age (Under 30) & $30-44$ & $0.184 * *(0.075)$ & 1.202 & $0.0170(0.065)$ & 1.017 \\
\hline & & $45-64$ & $0.0374(0.083)$ & 1.038 & $0.128 *(0.068)$ & 1.136 \\
\hline & & Above 65 & $-0.395 * *(0.193)$ & 0.674 & $0.209 * *(0.096)$ & 1.233 \\
\hline & Hometown inhabitants & $<10,000$ & $0.938 * * *(0.101)$ & 2.554 & $-0.708 * * *(0.098)$ & 0.493 \\
\hline & (Barcelona) & $10,000-50,000$ & $0.497 * * *(0.078)$ & 1.643 & $0.0182(0.055)$ & 1.018 \\
\hline & & $>50,000$ & $0.655 * * *(0.061)$ & 1.925 & $0.0301(0.041)$ & 1.031 \\
\hline \multirow[t]{13}{*}{ Economic } & Family monthly income $(<$ & $1000-2000 €$ & $0.449 * * *(0.109)$ & 1.566 & $-0.276^{* * *}(0.051)$ & 0.759 \\
\hline & $1000 €)$ & $2000-3000 €$ & $0.715 * * *(0.114)$ & 2.043 & $-0.543 * * *(0.063)$ & 0.581 \\
\hline & & $3000-4000 €$ & $0.821 * * *(0.127)$ & 2.272 & $-0.632 * * *(0.085)$ & 0.532 \\
\hline & & $4000-5000 €$ & $1.018 * * *(0.155)$ & 2.767 & $-0.784 * * *(0.132)$ & 0.456 \\
\hline & & $>5000 €$ & $1.372 * * *(0.161)$ & 3.942 & $-0.906 * * *(0.153)$ & 0.404 \\
\hline & Educational level (no studies) & Primary studies & $0.802 * * *(0.251)$ & 2.23 & $-0.382 * * *(0.075)$ & 0.682 \\
\hline & & Secondary studies & $1.122 * * *(0.253)$ & 3.072 & $-0.716^{* * *}(0.082)$ & 0.489 \\
\hline & & Tertiary studies & $1.007 * * *(0.256)$ & 2.737 & $-0.708 * * *(0.088)$ & 0.493 \\
\hline & Occupation status (student) & Housekeeper & $-0.367 *(0.214)$ & 0.692 & $0.901 * * *(0.113)$ & 2.462 \\
\hline & & Retiree & $-0.302(0.200)$ & 0.74 & $0.913 * * *(0.116)$ & 2.491 \\
\hline & & Employed & $0.761 * * *(0.133)$ & 2.14 & $-0.297 * * *(0.093)$ & 0.743 \\
\hline & & Unemployed & $0.0169(0.185)$ & 1.017 & $0.475 * * *(0.113)$ & 1.608 \\
\hline & $\begin{array}{l}\text { Observations } \\
\text { Pseudo } R^{2} \\
\text { Cox-Snell } R^{2} \\
\text { Nagelkerke } \\
\text { Hosmer-Lemeshow statistic (10 }\end{array}$ & roups) & $\begin{array}{r}16409 \\
0.122 \\
0.081 \\
0.165 \\
11.04 \text { (p-value } 0\end{array}$ & & $\begin{array}{c}16448 \\
0.137 \\
0.164 \\
0.225 \\
13.61 \text { (p-value } 0.09\end{array}$ & \\
\hline
\end{tabular}

Significance levels: * 10 per cent; $* * 5$ per cent; $* * * 1$ per cent (standard errors are presented in parentheses) Source: Authors

It was suggested above that the Seoul and Barcelona metropolitan areas have certain similarities in terms of their population density and economic performance. However, the respective results obtained in relation to high emitters differ somewhat. While Ko et al. (2011) report a pronounced U-shaped curve for age, we did not find the same effect. As for income, while both studies report the same pattern, the impact is much greater in our study. Likewise, the impact of the gender variable is much greater in the Barcelona area. As such, cultural factors combined with country- and city-specific citizen characteristics impact differently depending on the geographical zone.

\subsection{Mobility expenditure impacts}

The daily mobility survey seeks to provide a reliable sample of citizens' mobility patterns in the Barcelona metropolitan area and, to this effect, the results reported in the previous section and the impacts described do not contain any relevant bias. However, the observations available in this section correspond to a non-random selection, given that the share of citizens providing information about their mobility expenditure (1) corresponds to just a quarter of the above, and, more importantly, (2) the respondents are affected by some selection bias. ${ }^{10}$ In Table 5, we report the mean and standard deviation

${ }^{10} \mathrm{We}$ are aware that there is a potential problem of endogeneity between mobility expenditure and $\mathrm{CO}_{2}$ emissions. However, we believe this should not be a serious concern in this study. As explained above in section 3.1, neither fuel prices, tolls or parking pricing policies are decided in relation to $\mathrm{CO}_{2}$ emissions (or that of any other pollutant). Moreover, the vast majority of the survey population live in an area that is subject to an integrated mass transit fare, which is unrelated to emissions generated by the particular trip. Finally, in Spain, taxation on fuel is determined by the central government, and so there are no inter-territorial differences. Besides, central government has always been reluctant to introduce a carbon tax. Currently, the regional 
for several variables. It can be readily seen that this subsample has a higher proportion of high income earners, respondents are older than those in the overall whole sample, and the proportion of employed people is higher - in contrast to the frequency of students and homemakers. All these characteristics of the subsample are consistent with an upward bias in the proportion of high emitters - while $10 \%$ of individuals in the whole sample were high emitters, $17.3 \%$ are in this subsample. Hence, in the subsample high emitters are overrepresented. This bias cannot be corrected; thus, we need to be extremely cautious when interpreting our results. ${ }^{11}$

Table 5 Descriptive statistics

Table 5 Descriptive statistics
\begin{tabular}{|c|c|c|c|c|}
\hline \multirow{2}{*}{} & \multicolumn{2}{|c|}{ Sample } & \multicolumn{2}{c|}{$\begin{array}{c}\text { Subsample for mobility } \\
\text { expenditure variables }\end{array}$} \\
\cline { 2 - 5 } & Mean & Standard deviation & Mean & Standard deviation \\
\hline Emission household $\left(\mathrm{g} \mathrm{CO}_{2} /\right.$ day $)$ & 1582.9 & 2870.65 & 2704.1 & 3231.28 \\
\hline $\begin{array}{c}\text { Income (dummies) } \\
(2 \text { between 1000 and 2000 })\end{array}$ & 2.27 & 1.125 & 2.74 & 1.163 \\
\hline $\begin{array}{c}\text { Age (dummies) } \\
(4 \text { between 30 and 44 years) }\end{array}$ & 4.08 & 1.617 & 4.39 & 0.935 \\
\hline \% employed & 0.427 & 0.4947 & 0.713 & 0.4525 \\
\hline \% students & 0.246 & 0.4308 & 0.044 & 0.2045 \\
\hline \% housekeepers & 0.087 & 0.2813 & 0.033 & 0.1793 \\
\hline Observations & \multicolumn{3}{|c}{4002} \\
\hline
\end{tabular}

Source: Authors

Bearing in mind these caveats, the results in Table 6 suggest that expenditure on public transportation is a good measure of $\mathrm{CO}_{2}$ emissions in the case of the mobility variables: the higher the spending on public transport, the lower the carbon emission rates. ${ }^{12}$ This holds for almost all cases across all quantiles. Results for expenditure on car fuel and parking are always positive and significant for all quantiles: the higher the spending on fuel and parking, the higher the emissions of $\mathrm{CO}_{2}$. Furthermore, we find that lower emission rates are associated with higher expenditure on tolls. This result might seem counterintuitive at first sight, but we believe it to be a logical outcome in the case of the metropolitan area of Barcelona. While it might indeed be surprising if all motorways accessing the inner city of Barcelona were tolled, in reality only two out of eight access motorways are tolled. This means our result is consistent with a lower frequency of private car trips on access corridors served by the tolled motorways. Indeed, users of vehicles that are obliged to pay tolls are subject to a monetary disincentive to use their private vehicles, whereas travelers that use toll-free roads do not face the same monetary disincentive.

Parliament of Catalonia (in which the metropolitan area of Barcelona lies) is debating climate change legislation, which is likely to include a carbon tax on vehicles to be applied throughout the region. If the law is passed, the carbon tax will come into effect in 2018.

${ }^{11}$ It is worth noting that this type of bias is not exceptional among the surveys used in the studies described herein. For instance, the sample Ko et al. (2011) use in their study of the Seoul metropolitan area contains $54.7 \%$ males, a figure that is higher than the actual percentage of males in the population.

${ }^{12}$ Table-A1 reports a logistic regression for high- and non-emitters for the expenditure variables. 
Table 6 Quantile regression with mobility expenditure variables

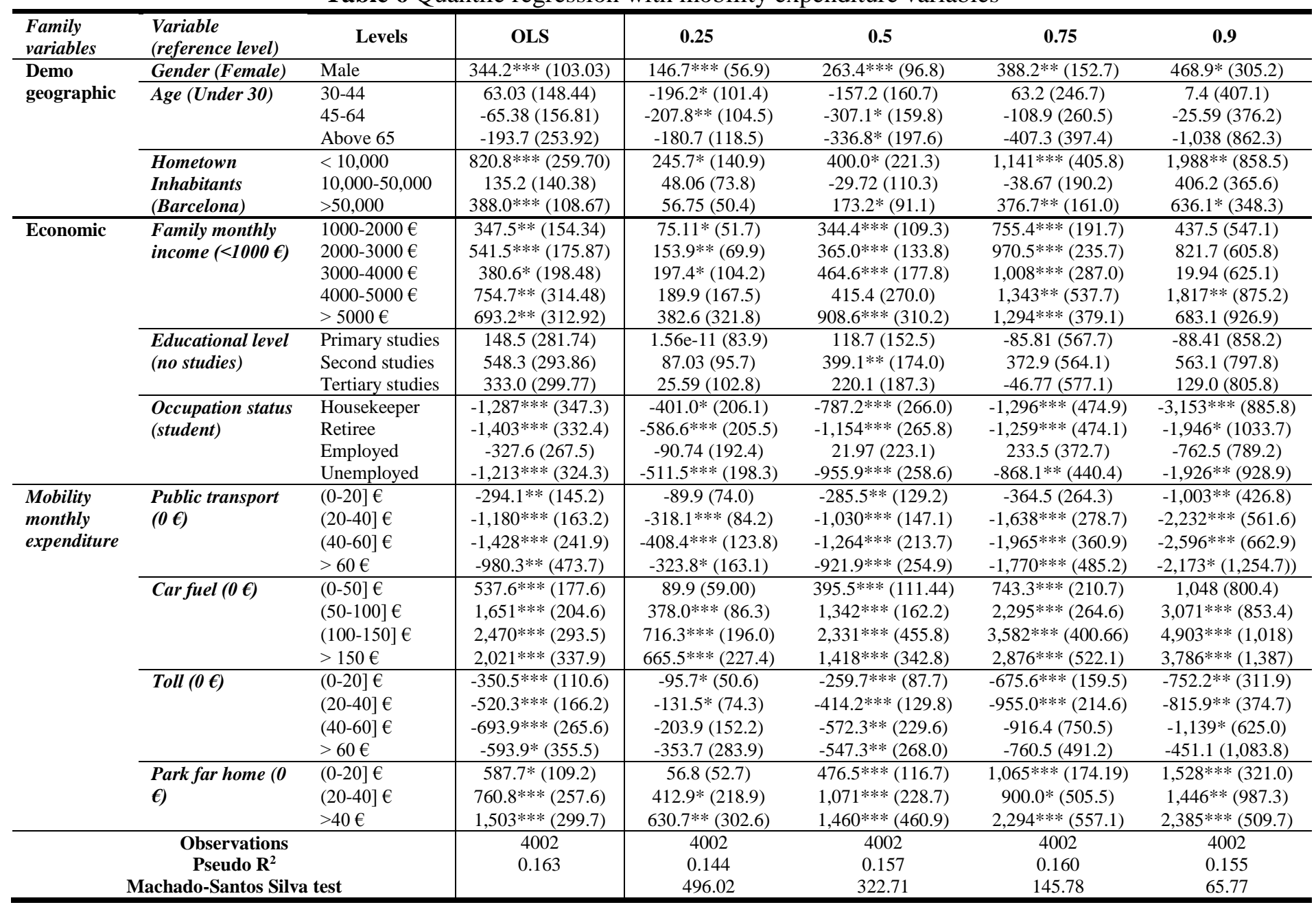

Significance levels: * 10 per cent; $* * 5$ per cent; *** 1 per cent (standard errors are presented in parentheses)

Source: Authors

Generally, we find similar patterns when comparing the OLS and quantile estimation results. However, a number of interesting differences emerge, especially when we examine the results for the mobility expenditure variables. In the case of expenditure on tolls, OLS values show a significant negative effect for all levels of expenditure, while quantile estimations indicate that non-emitters $(0.25)$ present little or no effect of tolls, reflecting the fact that these individuals probably make little use of private vehicles. For the highest level of expenditure on tolls, we find a very limited reaction for all groups of emitters, with the exception of the median group. The fact that the highest emitters with the highest toll expenditure show no significant reaction to tolls might reflect a lower demand-toll elasticity for the wealthiest private car users, which is consistent with the results linking the highest emitters with the highest levels of monthly income.

In the case of expenditure on parking away from the home, we also find interesting differences. Non-emitters present a lower reaction to parking expenditure, which is only highly significant for high levels of expenditure. Likewise, the coefficient (intensity) of the reaction to parking expenditure increases sharply when we consider groups of high emitters. These differences - as well as those related to toll expenditure - which cannot be observed from the OLS results, have interesting implications for public policy, as parking prices and tolls are two policies that local/regional authorities can regulate. 


\section{Discussion and policy implications}

Based on the information obtained from the quantile and logistic regressions, we can define the socioeconomic traits of the different emitters. Non-emitters tend to be female, retirees, homemakers and/or unemployed. Similarly, non-emitters tend to be older and to live in the inner city of Barcelona or in large neighboring towns. However, educational status is much more difficult to link to a specific pollutant profile. The profile of the low emitter is very similar to that of the non-emitter. In contrast, high emitters tend to be male, middle-aged, employed and residents of the smallest cities relatively far from the city of Barcelona.

In keeping with our expectations - taking into account the characteristics of our data, including outliers, skewed distribution, etc., the quantile regressions performed better than OLS regression, although we need to exercise some caution given the upward bias for high emitters in the mobility expenditure subsample. The coefficient signs tend to be similar for the different variables, but it is worth noting that the statistical significances differ when using quantile regressions. Interestingly, this is the case for toll expenditures and for spending on parking away from home. Likewise, notable differences are found in the intensity of the coefficients of these (as well as other) variables.

By employing quantile regression, we observe that impacts differ considerably across individuals. These impacts follow an increasing or decreasing trend (according to different socioeconomic traits), with few structural changes between quantiles, but with different impacts across them. Most socioeconomic factors do not have an equal influence on pollutant emitters of different levels; however, conventional methodologies are unable to assess this, as they only analyze average pollutant emitters or top emitters.

If we focus specifically on our mobility expenditure results, we find, in general, that expenditure on car fuel and parking is associated with higher $\mathrm{CO}_{2}$ emissions. In contrast, using public transportation is associated with lower emissions. The same is true of commuting on toll roads. Recall that just two of the eight inner city access motorways are tolled; hence, commuting on a toll road is likely to be associated with a lower usage of private vehicles. Beyond these general patterns, our quantile estimations reveal differences in significance and intensity (coefficients) between quantiles and regressions. Travelers that spend more on tolls and who are high emitters seem to be more reactive to tolls, although this does not hold for the highest level of expenditure. Similarly, the response to spending on parking away from home increases for travelers that spend more and who emit more.

These results should be of interest in devising more effective policies for the metropolitan area of Barcelona. While car fuel prices lie outside the control of local and metropolitan authorities, other policies can be implemented at the metropolitan level in relation to parking fees, tolls, and the supply and pricing of public transportation. Increasing parking charges in the inner city of Barcelona would help reduce emissions and the impact of this measure would be greatest among individuals that spend more on parking, and among those in the top emitting quantiles, as the results from our quantile regressions show. In the same vein, extending tolls to all motorways accessing the inner city should reduce the use of private vehicles and, thus, have the potential to reduce emissions. Our results suggest that this might not, however, be significant for the group of travelers that spend more on tolls and emit more; yet, decreasing congestion should also relieve the emissions of these travelers that use their private vehicles and who show little sensitivity to tolls. 
Clearly, suggesting that increasing parking away from home costs and introducing tolls on all access motorways would reduce emissions is unsurprising, as this outcome has been reported in many cities that have implemented measures of this type. Having said that, however, the results from our quantile regressions point to the particularly intense effect of such measures in the Barcelona metropolitan, given the coefficients reported for the high emitters' quantiles for expenditure on parking and (at least, until very high levels) on tolls. Furthermore, if the net revenues from these cost-increasing policies on parking and tolls were devoted to improving public transportation supply, this would further help reduce $\mathrm{CO}_{2}$ emissions.

Within this framework, we suggest that the application of the quantile regression methodology is of interest not only for scholarly analysis, but also for policy making particularly policies designed to have long-term effects. In practice, household travel surveys are available for most large conurbations, which means the $\mathrm{CO}_{2}$ emissions of each trip can be calculated and the data treated with quantile regression so that specific analyses can be undertaken for all areas. This means quantile regression is a methodology that governments can use to improve their understanding of the socioeconomic profile of different types of emitter in different population groups and this information should help them design effective and specific transport policies to mitigate the greenhouse effect.

\section{Conclusion}

Cutting $\mathrm{CO}_{2}$ emissions attributable to urban mobility has become a challenge for large cities. This paper has sought to address a gap in the literature by comparing different emitters of carbon dioxide by mode of transport and in terms of their socioeconomic characteristics. An examination of the personal factors affecting the modal share has been undertaken in recent years, but conventional models encounter difficulties in explaining travel patterns and behavior, since the latter vary according to lifestyles, personal preferences and attitudes. Indeed, certain characteristics are significant in accounting for factors that affect $\mathrm{CO}_{2}$ mobility emissions.

Our research contributes to the literature by adopting an innovative methodology - that of, quantile regression - to explain the relation between socioeconomic variables and transport emissions in urban areas according to different levels of emission. In so doing, we contribute to filling the gap in the knowledge of differences between $\mathrm{CO}_{2}$ high emitters, average emitters, low emitters and non-emitters.

Based on our analysis of socioeconomic characteristics across quantiles of pollutant individuals, and the impact we report for variables related to mobility expenditure, we have been able to confirm the potential impact of several measures that could be highly effective in reducing emissions in the case of Barcelona, as well as to gain a better understanding of their effects on different groups of emitters. As such, quantile analysis appears to be a useful tool for analyzing the behavior of groups of emitters in different urban conurbations. We recommend that governments analyze available data from travel surveys using quantile regressions to verify whether their mobility policies are being effectively implemented, and to obtain a clearer picture of their potential impacts on different groups of emitters.

The household travel survey data used here have several shortcomings. First, we have insufficient information to compute the $\mathrm{CO}_{2}$ emissions of commuters that use more than 
one travel mode and so we were forced to omit these journeys. This reduced the available number of observations by $20 \%$. Indeed, future surveys would be greatly improved if they asked respondents to indicate where they changed modes of transport. Second, data are unavailable for some socioeconomic characteristics, including private vehicle ownership and household size. And third, the sample bias with regard to mobility expenditure means high-emitters - that is, males, in employment and with high incomes - are overrepresented. However, it is our belief that these shortcomings have not seriously affected our main findings and conclusions.

The type of analysis conducted here should be an effective tool for analyzing mobility behavior in different metropolitan areas. Indeed, if other cities can begin to fill this information gap, they should be able to make more accurate and more correct policy decisions. Indeed, we are aware, as shown by a sizable body of evidence in the literature, that most of the $\mathrm{CO}_{2}$ emissions related to mobility are attributable to factors and attitudes intrinsic to each person, which means an individual's socioeconomic characteristics only account for a part of this variability. Mobility patterns differ from one city to another as do the socio-economic characteristics of their respective citizens.

\section{References}

Allinson, D., Irvine, K. N., Edmondson, J. L., Tiwary, A., Hill, G., Morris, J. \& Gaston, K. J. (2016). Measurement and analysis of household carbon: The case of a UK city. Applied Energy, 164, 871-881.

Anable, J., (2005). 'Complacent car addicts' or 'aspiring environmentalists'? Identifying travel behaviour segments using attitude theory. Transport Policy, 12, 65-78.

Barla, P., Miranda-Moreno, L. F., \& Lee-Gosselin, M. (2011). Urban travel $\mathrm{CO}_{2}$ emissions and land use: A case study for Quebec City. Transportation Research Part D: Transport and Environment, 16(6), 423-428.

Bel, G., Bolancé, C., Guillén, M. \& Rosell, J. (2015). The environmental effects of changing speed limits: a quantile regression approach. Transportation Research Part D: Transport and Environment, 36, 76-85.

Brand, C. \& Boardman, B. 2008. Taming of the few - the unequal distribution of greenhouse gas emissions from personal travel in the UK. Energy Policy, 36(1), 224-238.

Brand, C., Goodman, A., Rutter, H., Song, Y., \& Ogilvie, D. (2013). Associations of individual, household and environmental characteristics with carbon dioxide emissions from motorised passenger travel. Applied Energy, 104, 158-169.

Brand, C. \& Preston, J.M. (2010). “60-20 emission"- The unequal distribution of greenhouse gas emissions from personal, non-business travel in the UK. Transport Policy, 17, 9-19.

Büchs, M., \& Schnepf, S.V. (2013). Who emits most? Associations between socioeconomic factors and UK households' home energy, transport, indirect and total $\mathrm{CO}_{2}$ emissions. Ecological Economics, 90, 114-123. 
Chapman, L. (2007). Transport and climate change: a review. Journal of Transport Geography, 15(5), 354-367.

Deaton, A. (1997). The Analysis of Household Surveys - A Microeconometric Approach to Development Policy. The John Hopkins University Press, London.

Duro, J. A., \& Padilla, E. (2006). International inequalities in per capita $\mathrm{CO}_{2}$ emissions: a decomposition methodology by Kaya factors. Energy Economics, 28(2), 170-187.

Duro, J. A., \& Padilla, E. (2011). Inequality across countries in energy intensities: an analysis of the role of energy transformation and final energy consumption. Energy Economics, 33(3), 474-479.

Garcia-López, M. À. (2010). Population suburbanization in Barcelona, 1991-2005: Is its spatial structure changing? Journal of Housing Economics, 19(2), 119-132.

Gragera, A., \& Albalate, D. (2016). The impact of curbside parking regulation on garage demand. Transport Policy, 47, 160-168

Greening, L. A. (2004). Effects of human behavior on aggregate carbon intensity of personal transportation: comparison of 10 OECD countries for the period 19701993. Energy Economics, 26(1), 1-30.

Hammoudeh, S., Nguyen, D. K., \& Sousa, R. M. (2014). Energy prices and $\mathrm{CO}_{2}$ emission allowance prices: A quantile regression approach. Energy Policy, 70, 201-206.

Han, L., Xu, X., \& Han, L. (2015). Applying quantile regression and Shapley decomposition to analyzing the determinants of household embedded carbon emissions: evidence from urban China. Journal of Cleaner Production, 103, 219230.

Institut d'Estudis Regionals i Metropolitans de Barcelona (IERMB). (2006). Enquesta de Mobilitat Quotidiana 2006. https://iermb.uab.cat/ca/enquestes/enquestes-demobilitat/IERM, Barcelona.

IEA (2015). $\mathrm{CO}_{2}$ Emissions from Fuel Combustion 2015. OECD Publishing, Paris.

International Transport Forum (2009). Reducing Transport GHG Emissions: Opportunities and Costs, Preliminary Findings. OECD, Paris.

Ko, J., Park, D., Lim, H., \& Hwang, I.C. (2011). Who produces the most $\mathrm{CO}_{2}$ emissions for trips in the Seoul metropolis area? Transportation Research Part D: Transport and Environment, 16(5), 358-364.

Koenker, R. (2004). Quantile regression for longitudinal data, Journal of Multivariate Analysis, 91, 74-89.

Koenker, R. \& Bassett, G. (1978). Regression quantiles, Econometrica, 46, 33-50.

Machado, J.A.F., Parente, P.M.D.C., and Santos Silva, J.M.C. (2011), QREG2: Stata module to perform quantile regression with robust and clustered standard errors, 
Statistical Software Components S457369. Boston College Department of Economics, Boston (MA).

Machado, J.A.F. \& Santos Silva, J.M.C. (2000), Glejser's Test Revisited, Journal of Econometrics, 97(1), 189-202.

Muñiz, I., \& Galindo, A. (2005). Urban form and the ecological footprint of commuting. The case of Barcelona. Ecological Economics, 55(4), 499-514.

Mussini, M., \& Grossi, L. (2015). Decomposing changes in CO 2 emission inequality over time: The roles of re-ranking and changes in per capita $\mathrm{CO}_{2}$ emission disparities. Energy Economics, 49, 274-281.

Reichert, A., Holz-Rau, C., \& Scheiner, J. (2016). GHG emissions in daily travel and long-distance travel in Germany-Social and spatial correlates. Transportation Research Part D: Transport and Environment, 49, 25-43.

Santos, G., Maoh, H., Potoglou, D. \& von Brunn, T. (2013). Factors influencing modal split of commuting journeys in medium-size European cities. Journal of Transport Geography, 30, 127-137.

$\mathrm{Su}, \mathrm{Q}$. (2012). A quantile regression analysis of the rebound effect: Evidence from the 2009 National Household Transportation Survey in the United States. Energy Policy, 45, 368-377.

Timmermans, H., van der Waerden, P., Alves, M., Polak, J., Ellis, S., Harvey, A.S. \& Zandee, R. (2003). Spatial context and the complexity of daily travel patterns: an international comparison. Journal of Transport Geography, 11(1), 37-46.

Xiao, Z., Lenzer, J. H., \& Chai, Y. (forthcoming). Examining the uneven distribution of household travel carbon emissions within and across neighborhoods: the case of Beijing. Journal of Regional Science, forthcoming, DOI 10.1111/jors.12278

Zahabi, S. A. H., Miranda-Moreno, L., Patterson, Z., \& Barla, P. (2015). Spatio-temporal analysis of car distance, greenhouse gases and the effect of built environment: A latent class regression analysis. Transportation Research Part A: Policy and Practice, 77, 1-13. 


\section{APPENDIX}

Table A1 Logistic regressions with mobility expenditures

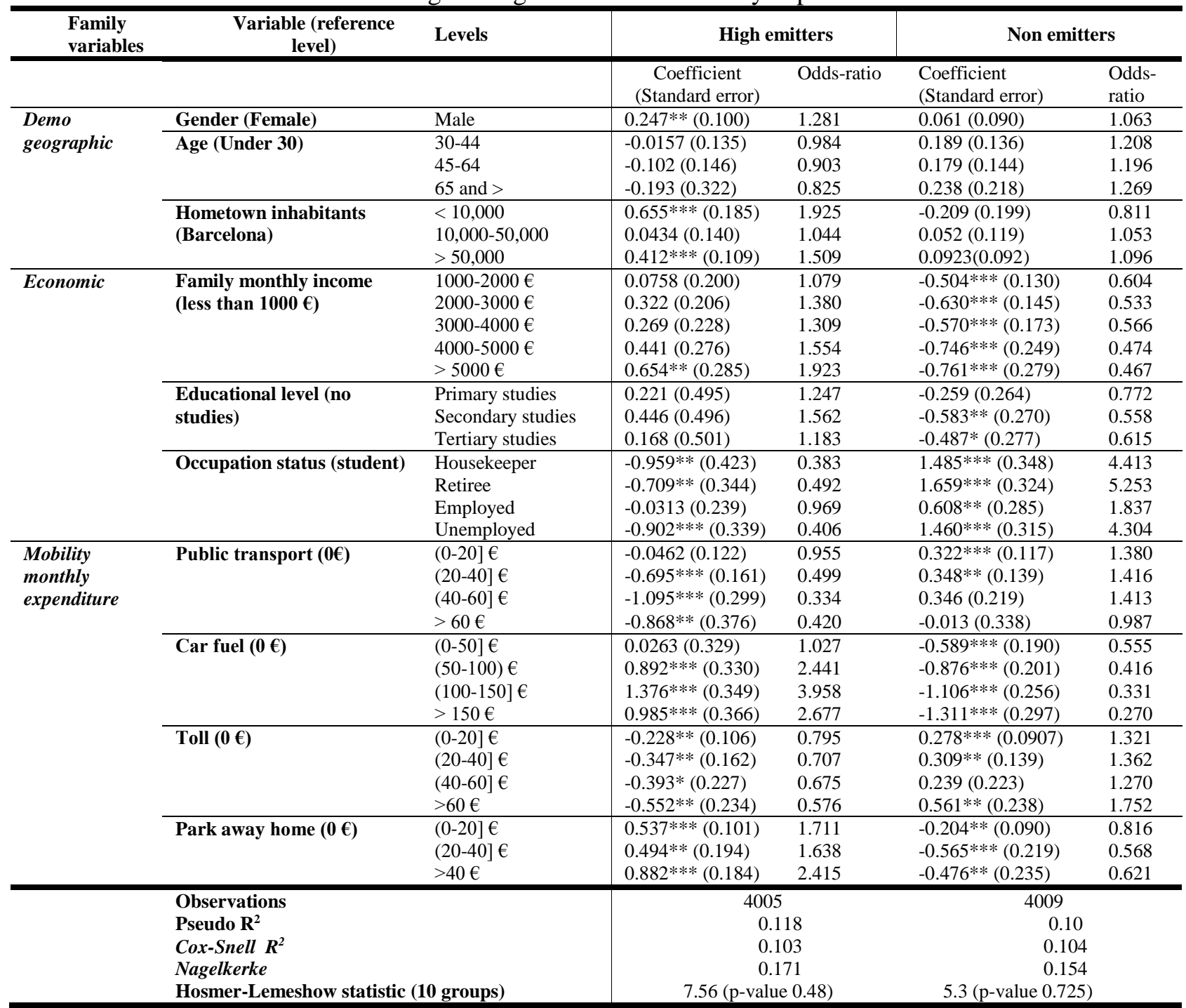

Significance levels: * 10 per cent; ** 5 per cent; *** 1 per cent (standard errors are presented in parentheses)

Source: Authors 